\section{Hygiene \\ Scharf - Schnell - Sicher und hygienisch einwandfrei}

Durch die aktuellen Hygienerichtlinienverordnungen und gefordertes QM-Management in den Praxen werden rotierende Instrumente immer teurer. Nicht im Anschaffungspreis, aber durch zusätzliche, interne Handlingkosten. Vorschriftsmäßig autoklaviert und mit entsprechenden Vermerken eingetragen, kostet jeder Bohrer in einer Vollkostenrechnung mit anteiligen Personalkosten für Handling und Administrationsvorgänge, Neuverpackung, Geräteabschreibungen und Strom für den Steri für jede Neuaufbereitung zwischen 2,25 und 2,70 €. Gleichzeitig verlieren alle rotierenden Instrumente mit jeder erneuten Verwendung an Schneidleistung. Dadurch dauert die darauf folgende Behandlungstätigkeit in der Regel länger. Der abnehmende Rundlauf des Instruments und der zunehmende Anpressdruck durch die stumpfer werdenden Schneiden sorgen zusätzlich für mehr Abnutzungserscheinungen im Handstück und erhöhen in diesem Bereich mittelfristig die Wartungs- bzw. Neuanschaffungskosten.

Diese versteckten Kosten lassen sich mit der Nutzung eines immer hygienischen und immer scharfen Einmalinstruments vermeiden: Die Hartmetall-Universalbohrer Talon 10 und Talon 12 von TriHawk werden steril verpackt geliefert, sind einzeln entnehmbar und liegen mit einem Anschaffungspreis von 3,69 $€$ nur $1,00 €$ über dem Preis einer kompletten Aufbereitung. Praktisch dabei: Durch die vielfältigen Indikationsbereiche der Talon-Bohrer entfällt ständiges Wechseln im Handstück und die Anschaffung vieler verschiedener Formen, was den Investitionsbedarf erheblich senkt. Dank seines spezi-

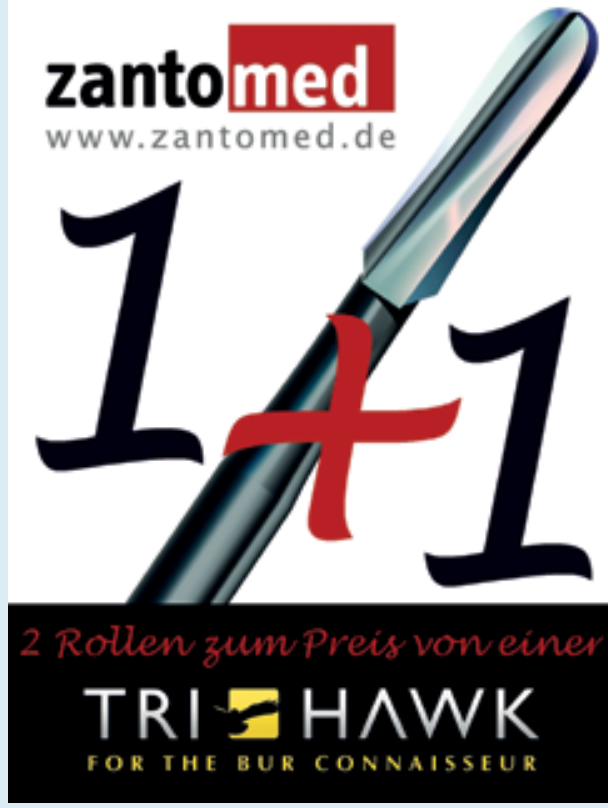

ellen Schliffs lässt sich der Talon sowohl horizontal als auch vertikal ansetzen. Er arbeitet sich durch Schmelz und Dentin aber auch durch Amalgam, Titan, Kronen und Brücken aus EM oder NEM.

Seit dem 01. Juli 2014 sind sämtliche Modelle der TriHawk-Bohrer exklusiv über die Zantomed GmbH in Duisburg oder den qualifizierten Dentalfachhandel zu beziehen. Noch bis Ende November hält der Anbieter ein attraktives 1+1 Angebot aufrecht, sodass jede Praxis $1 \mathrm{x}$ die Möglichkeit hat für einen risikofreien Einkauf zum halben Preis. (1+1-Angebot nur direkt über Zantomed zu beziehen).

Nach einer Pressemitteilung der Zantomed GmbH, Duisburg Internet: www.zantomed.de 